Alberto Sosa-Olavarria, Jesús Zurita-Peralta, Claudio V. Schenone, Mauro H. Schenone* and Fernando Prieto

\title{
Doppler evaluation of the fetal pulmonary artery pressure
}

https://doi.org/10.1515/jpm-2018-0112

Received March 30, 2018; accepted October 22, 2018; previously published online November 15, 2018

\section{Abstract}

Background: The Doppler effect has allowed the characterization of several vessels in maternal-fetal circulation that have been used for practical purposes. Our review of the literature showed a paucity of information about fetal pulmonary artery pressure (FMPAP) and its behavior in regard to gestational age (GA). The objectives of the study were to evaluate a formula to calculate the main FMPAP and its correlation with GA.

Methods: A total of 337 fetuses without obvious pathology were studied prospectively using Doppler evaluation of the FMPAP. Using the fetal main pulmonary artery Doppler acceleration time (FMPAT), we obtained the FMPAP using the following formula: FMPAP $=90-(0.62 \times$ FMPAT $)$. Regression analyses, Pearson's bivariate correlation and paired sample $t$-test were used when appropriate.

Results: FMPAT increases while FMPAP decreases with GA. Pearson's correlation coefficient for FMPAP and GA was -0.544 (P-value <0.001) and for FMPAT and GA was 0.556 (P-value $<0.001$ ). FMPAP and FMPAT were highly correlated $(\mathrm{R}=-0.972 ; \mathrm{P}<0.001)$.

Conclusion: Pulmonary artery pressure in the fetus decreases with GA.

Keywords: Doppler; fetal pulmonary artery pressure; pulmonary hypertension; pulmonary vasculature impedance.

*Corresponding author: Mauro H. Schenone, MD, University of Tennessee Health and Science Center, 853 Jefferson Avenue, Suite E102 Memphis, TN 38163, USA, Tel.: (+901) 448-2531, Fax: (+901) 448-4701, E-mail: mschenon@uthsc.edu Alberto Sosa-Olavarria and Fernando Prieto: Unidad de Diagnostico Perinatal (UDP)-Centro Policlínico Valencia (CPV), Valencia, Venezuela

Jesús Zurita-Peralta: Instituto de Cardiologia/Fundacion Universitaria de Cardiologia, Porto Alegre, RS, Brazil Claudio V. Schenone: University of Tennessee Health and Science Center, Memphis, TN, USA

\section{Introduction}

The Doppler effect allows the measurement of many variables associated with fetal hemodynamics. Such measurements have permitted the characterization of many vessels in maternal-fetal circulation and thus monitor maternal and fetal condition and wellbeing. Several studies have reported reference values for variables such as systolic and diastolic velocities, pulsatility index, acceleration time, deceleration time and ejection time for gestational age (GA). Some of these have been used for practical purposes, such as methods of predicting fetal lung maturity $[1,2]$.

The importance of Doppler as a non-invasive method of estimating the pulmonary artery pressure in neonates and adults has been demonstrated in numerous studies [3-7]. In the fetus, the Doppler evaluation of the main pulmonary artery has been shown to be useful in the analysis of the impedance of such vascular systems and changes in those variables have been demonstrated to correlate with GA, fetal lung maturity and neonatal outcomes [1, 2, 8-11]. Our review of the literature showed a lack of information about fetal main pulmonary artery pressure (FMPAP) and its behavior in regard to GA.

Several formulas have been proposed in order to estimate the pulmonary artery pressure using the Doppler wave acceleration time [12-18]. Dabestani et al. found excellent correlation $(\mathrm{R}=0.98)$ between the formula [pulmonary artery pressure $=90-(0.62 \times$ fetal main pulmonary artery acceleration time)] and the actual pulmonary artery pressure [19].

In this study, we aimed to evaluate the estimated FMPAP calculated using the formula proposed by Dabestani et al. [19] and its correlation with GA.

\section{Materials and methods}

This study was approved by the Ethics Committee of the hospital in which the patients were enrolled from Centro Policlínico Valencia (CPV). This is a prospective study that included 337 pregnant women considered low risk and well dated (first trimester ultrasound). These cases were managed in the Unidad de Diagnostico Perinatal (UDP)-CPV, Venezuela. During the period of January-April 2015. 
Three hundred and thirty seven fetuses between 13 and 38 weeks of gestation and considered normal were assessed with Doppler. Such fetuses showed a normal growth pattern and no significant morbidity were noted in the first $72 \mathrm{~h}$ of life.

The Doppler evaluation was obtained using pulse wave Doppler and interrogating the fetal main pulmonary artery in the area next to the opening of the pulmonary valve. The angle of insonation was maintained at less than 30 degrees. Once the waves were obtained, the fetal main pulmonary artery acceleration time (FMPAT) in milliseconds was measured in at least six waves and an average was calculated. Acceleration time is defined as the time period from the onset of systolic flow through the pulmonary valve to the peak systolic velocity. The ultrasound system used was the Esaote MyLab Twice (transducer BC431) (Esaote, Genoa, Italy). The FMPAT was used in the formula: FMPAP $=90-(0.62 \times$ FMPAT $)$. The intraobserver reliability of the acceleration time measurement was calculated utilizing the intraclass correlation in 100 cases.

A P-value of $<0.05$ was used to determine statistical significance. Data were analyzed using quadratic curve regression. Pearson's bivariate correlation was used when appropriate. A paired sample $t$-test was used to compare the mean FMPAT and FMPAP of cases at 34 and those at 38 weeks of gestation. The analyses were performed using SPSS 13.0 (SPSS Inc., Chicago, USA). The results are presented in tables and graphs.

\section{Results}

The estimated FMPAP decreased as GA advanced. The FMPAT increased with advancing GA. This is shown in Figures 1 and 2. Both estimated arterial pressure and acceleration time were significantly correlated with GA ( $R-0.544$ and 0.556, respectively; $\mathrm{P}$-value $<0.001$ ).

As expected (given the formula used), the FMPAP and the FMPAT were highly correlated $\left(\mathrm{R}^{2}-0.972\right.$; $\mathrm{P}$-value < 0.001).

Thirty cases at 34 weeks of gestation were compared with 30 cases at 38 weeks of gestation and a

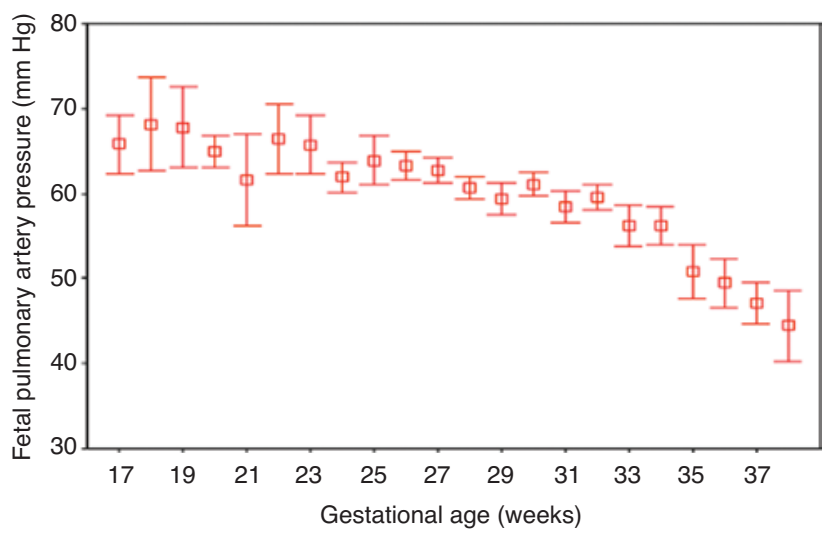

Figure 1: Fetal pulmonary artery pressure and gestational age [mean and $95 \%$ confidence interval $(\mathrm{Cl})$ ].

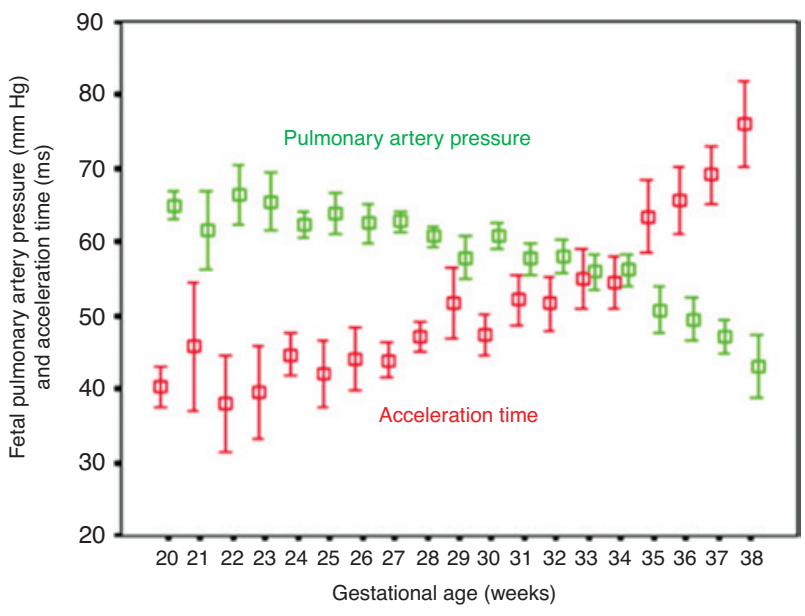

Figure 2: Fetal pulmonary artery pressure and acceleration time according to gestational age (mean and $95 \% \mathrm{Cl}$ ).

significant difference was noticed in FMPAT (54.51 \pm 11.20 vs. $76.03 \pm 15.79 \mathrm{~ms}$, respectively) and FMPAP $(76.03 \pm 15.79$ vs. $43.10 \pm 11.69 \mathrm{~mm} \mathrm{Hg}$, respectively); $(\mathrm{P}<0.001)$ (see Figure 3).

\section{Discussion}

The results of this study suggest that the estimated FMPAP calculated using the formula above, decreases with advancing GA. This finding supports previous reports that show a decreased impedance in the pulmonary vasculature as the fetus approaches term, as well as the potential utility of the formula proposed by Dabestani et al. in the estimation of FMPAP $[1,2,9,11,20]$.

Using a non-invasive estimation of the MFPAP may help predict whether neonatal pulmonary hypertension

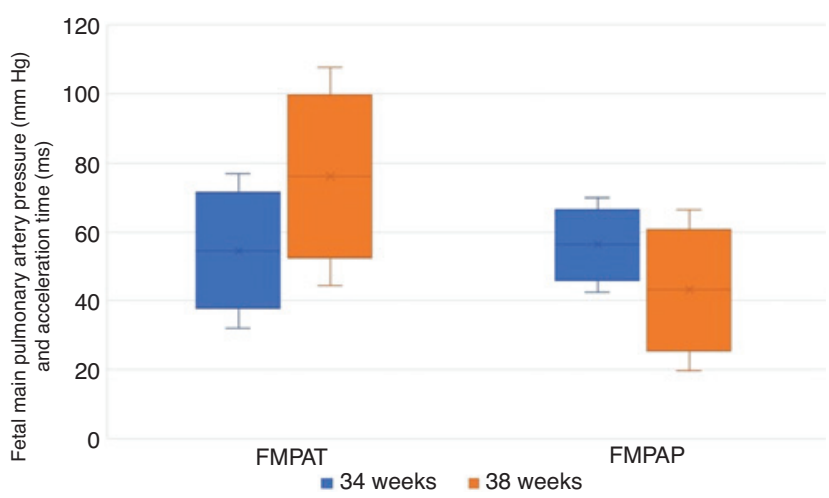

Figure 3: Comparison of fetal main pulmonary artery pressure (FMPAP) and acceleration time (FMPAT) between groups at 34 and 38 weeks of gestation. 
will be diagnosed postnatally. This hypothesis is being evaluated by our group. Prognosis and prediction of pulmonary hypertension in cases of congenital diaphragmatic hernia may represent a practical example of the applicability of the method [21].

The work by Kitabatake et al. [14] suggested a way of measuring the pulmonary artery pressure by using Doppler velocimetry and in this publication, reference is made to previous authors [17, 22-24] who proposed abnormalities in the movement of the pulmonary valve in cases of pulmonary hypertension. These abnormalities in movement of the pulmonary valve included a rapid systolic opening with decreased or absence of the "a" and a prolongation of the right ventricle pre-ejection/ejection time ratio. Kitabatake et al. [14] reported a negative correlation $(-0.90)$ between acceleration time/ejection time ratio of the pulmonary artery and the pulmonary artery pressure in postnatal cases.

Our group has previously reported a progressive prolongation of the acceleration time and therefore an increase in AT/ET ratio as GA advances [2]. In addition, we previously published a positive correlation between AT/ET ratio (PATET) with lung maturity testing via amniocentesis [1]. However, to the best of our knowledge this study is the first one to report estimates of FMPAP non-invasively by using Doppler evaluation and using the formula described.

Martin-Duran et al. [15] reported that the analysis of the pulmonary flow is a reliable tool in the evaluation of the pulmonary pressure; especially, when evaluating the total pulmonary resistance. Furthermore, they report the acceleration time as the variable that correlates best.

Subhedar and Shaw [25] reported that the pulmonary artery pressure in neonates with respiratory distress syndrome is increased and it decreases as this resolves. The contrary happens when the condition evolves into chronic lung disease [16].

As a valid alternative to evaluate the pulmonary vascular resistance Chaoui et al. [20] reported the use of numerical variables to apply over the pulmonary Doppler wave including the acceleration/ejection time ratio. This ratio correlates inversely with the arterial pressure of the vessel being evaluated. Kitabatake et al. [14] reported similar results. Granstam et al. [12] reported that values of acceleration time $<100 \mathrm{~ms}$ indicate a high probability of pulmonary hypertension.

In conclusion, the Doppler velocimetry has demonstrated to be of utility when evaluating not only fetal pulmonary maturity but now we have some evidence to suggest its utility in evaluating the FMPAP and we hypothesize that further studies may prove that estimates of the MFPAP may predict whether or not the neonate will develop pulmonary hypertension.
Author contributions: All the authors have accepted responsibility for the entire content of this submitted manuscript and approved submission.

Research funding: None declared.

Employment or leadership: None declared.

Honorarium: None declared.

Competing interests: The funding organization(s) played no role in the study design; in the collection, analysis, and interpretation of data; in the writing of the report; or in the decision to submit the report for publication.

\section{References}

1. Schenone MH, Samson JE, Jenkins L, Suhag A, Mari G. Predicting fetal lung maturity using the fetal pulmonary artery Doppler wave acceleration/ejection time ratio. Fetal Diagn Ther 2014;36:208-14.

2. Sosa-Olavarria A, Diaz-Guerrero L. Indice relativo de impedancia Doppler de la arteria pulmonar y del ductus arterioso en embarazos pretermino, a terminio y post-termino. Revista de Obstetrica y Ginecologica de Venezuela 2000;60:97-101.

3. Koestenberger M, Apitz C, Abdul-Khaliq H, Hansmann G. Transthoracic echocardiography for the evaluation of children and adolescents with suspected or confirmed pulmonary hypertension. Expert consensus statement on the diagnosis and treatment of paediatric pulmonary hypertension. The European Paediatric Pulmonary Vascular Disease Network, endorsed by ISHLT and D6PK. Heart 2016;102(Suppl 2):ii 14-22.

4. Orji FT, Adiele DK, Umedum NG, Akpeh JO, Ofoegbu VC, Nwosu $J N$. The clinical and radiological predictors of pulmonary hypertension in children with adenotonsillar hypertrophy. Eur Arch Otorhinolaryngol 2017;274:1237-43.

5. Howard LS, Grapsa J, Dawson D, Bellamy M, Chambers JB, Masani ND, et al. Echocardiographic assessment of pulmonary hypertension: standard operating procedure. Eur Respir Rev 2012;21:239-48.

6. Kirkpatrick EC. Echocardiography in pediatric pulmonary hypertension. Paediatr Respir Rev 2013;14:157-64.

7. Fakhri AA, Hughes-Doichev RA, Biederman RW, Murali S. Imaging in the evaluation of pulmonary artery hemodynamics and right ventricular structure and function. Heart Fail Clin 2012;8:353-72.

8. Azpurua H, Norwitz ER, Campbell KH, Funai EF, Pettker CM, Kleine $\mathrm{M}$, et al. Acceleration/ejection time ratio in the fetal pulmonary artery predicts fetal lung maturity. Am J Obstetr Gynecol 2010;203:40 e1-8.

9. Guan Y, Li S, Luo G, Wang C, Norwitz ER, Fu Q, et al. The role of doppler waveforms in the fetal main pulmonary artery in the prediction of neonatal respiratory distress syndrome. J Clin Ultrasound 2015;43:375-83.

10. Kim SM, Park JS, Norwitz ER, Hwang EJ, Kang HS, Park CW, et al. Acceleration time-to-ejection time ratio in fetal pulmonary artery predicts the development of neonatal respiratory distress syndrome: a prospective cohort study. Am J Perinatol 2013;30:805-12. 
11. Moety GA, Gaafar HM, El Rifai NM. Can fetal pulmonary artery Doppler indices predict neonatal respiratory distress syndrome? J Perinatol 2015;35:1015-9.

12. Granstam SO, Bjorklund E, Wikstrom G, Roos MW. Use of echocardiographic pulmonary acceleration time and estimated vascular resistance for the evaluation of possible pulmonary hypertension. Cardiovasc Ultrasound 2013;11:7.

13. Guerra Ramos FJ. Role of echocardiography in suspected pulmonary hypertension. Arch Bronconeumol 2011;47(Suppl 7):7-11.

14. Kitabatake A, Inoue M, Asao M, Masuyama T, Tanouchi J, Morita T, et al. Noninvasive evaluation of pulmonary hypertension by a pulsed Doppler technique. Circulation 1983;68:302-9.

15. Martin-Duran R, Larman M, Trugeda A, Vazquez de Prada JA, Ruano J, Torres A, et al. Comparison of Doppler-determined elevated pulmonary arterial pressure with pressure measured at cardiac catheterization. Am J Cardiol 1986;57:859-63.

16. Murase M, Ishida A. Serial pulsed Doppler assessment of pulmonary artery pressure in very low birth-weight infants. Pediatr Cardiol 2000;21:452-7.

17. Nanda NC, Gramiak R, Robinson TI, Shah PM. Echocardiographic evaluation of pulmonary hypertension. Circulation 1974;50:575-81.

18. Yared K, Noseworthy P, Weyman AE, McCabe E, Picard MH, Baggish AL. Pulmonary artery acceleration time provides an accurate estimate of systolic pulmonary arterial pressure during transthoracic echocardiography. J Am Soc Echocardiogr 2011;24:687-92.

19. Dabestani A, Mahan G, Gardin JM, Takenaka K, Burn C, Allfie A, et al. Evaluation of pulmonary artery pressure and resistance by pulsed Doppler echocardiography. Am J Cardiol 1987;59:662-8.

20. Chaoui R, Taddei F, Rizzo G, Bast C, Lenz F, Bollmann R. Doppler echocardiography of the main stems of the pulmonary arteries in the normal human fetus. Ultrasound ObstetGynecol 1998;11:173-9.

21. Done E, Debeer A, Gucciardo L, Van Mieghem T, Lewi P, Devlieger $\mathrm{R}$, et al. Prediction of neonatal respiratory function and pulmonary hypertension in fetuses with isolated congenital diaphragmatic hernia in the fetal endoscopic tracleal occlusion era: a single-center study. Fetal Diagn Ther 2015;37:24-32.

22. Hirschfeld S, Meyer R, Schwartz DC, Kofhagen J, Kaplan S. The echocardiographic assessment of pulmonary artery pressure and pulmonary vascular resistance. Circulation 1975;52:642-50.

23. Lew W, Karliner JS. Assessment of pulmonary valve echogram in normal subjects and in patients with pulmonary arterial hypertension. Br Heart J 1979;42:147-61.

24. Weyman AE, Dillon JC, Feigenbaum H, Chang S. Echocardiographic patterns of pulmonic valve motion with pulmonary hypertension. Circulation 1974;50:905-10.

25. Subhedar NV, Shaw NJ. Changes in pulmonary arterial pressure in preterm infants with chronic lung disease. Arch Dis Child Fetal Neonatal Ed 2000;82:F243-7. 